\title{
Aplikasi Market Matching Berbasis Fuzzy sebagai Penunjang Keputusan Ekspor Produk UMKM
}

\author{
Bambang Nurdewanto, Elta Sonalitha, Fikri Amrullah, Salnan Ratih
}

\begin{abstract}
Determining the exact location of the export market with the right amount in the marketing process is expected to reduce the number of losses due to the stagnancy of product turnover. Appropriate target market system using fuzzy control on MSMEs. Fuzzy control method is used to overcome the determination of a market that is influenced by the subjectivity of marketing actors. Online market matching application which is the right decision support system of the right export destination and the right amount so efficient. The result of market matching application of fuzzy method is recommendation of destination and quantity that can be exported.
\end{abstract}

Index Terms -Export, Fuzzy, Market Matching, MSME.

Abstrak-- Penentuan lokasi pasar ekspor yang tepat dengan jumlah yang tepat pada proses pemasaran diharapkan dapat menekan angka kerugian akibat tersendatnya perputaran produk. Sistem penentuan target market yang tepat menggunakan kontrol fuzzy pada UMKM. Metode fuzzy control digunakan untuk mengatasi penentuan market yang dipengaruhi oleh subyektifitas pelaku pemasaran. Aplikasi market matching online yang merupakan sistem penunjang keputusan tujuan ekspor yang tepat dan jumlah yang tepat sehingga efisien. Hasil aplikasi market matching metode fuzzy berupa rekomendasi tujuan dan jumlah yang dapat diekspor.

Kata Kunci-Ekspor, Fuzzy, Market matching, UMKM.

B. N. Fakultas Teknologi Informasi Universitas Merdeka Malang, Terusan Raya Dieng 62-62, Malang, 65142, Indonesia (e-mail: nurdewa@unmer.ac.id)

E. S. Fakultas Teknologi Informasi Universitas Merdeka Malang, Terusan Raya Dieng 62-62, Malang, 65142, Indonesia (e-mail: elta.sonalitha@unmer.ac.id)

F. A. Fakultas Teknologi Informasi Universitas Merdeka Malang, Terusan Raya Dieng 62-62, Malang, 65142, Indonesia

S. R. (e-mail: salnanratih@gmail.com).

\section{PENDahuluan}

$\mathrm{B}$ EBERAPA kendala ekspor produk UMKM adalah dalam perputaran produk yang lambat di negaranegara importir dikarenakan stok produk tidak segera habis terjual di Negara tersebut dan terkadang sampai mencapai batas kadaluarsa. Hal ini disebabkan karena tidak adanya informasi mengenai perkembangan lokasi pasar dan persaingan UMKM dengan produk yang sama.

Kebijakan pasar bebas ASEAN tentu akan mempengaruhi peta perekonomian dan persaingan pasar domestik dengan produk yang datang dari negaranegara tetangga. Jika tak ada langkah serius dari pemerintah dan UMKM itu sendiri, bukan tidak mungkin produk dan usaha-usaha dalam negeri akan kalah saing dengan produk dan usaha-usaha negeri tetangga. Untuk menghadapi kondisi yang semakin kompleks tersebut, tentunya UMKM yang unggul harus mampu memenuhi poin-poin ini, antara lain : Kemampuan dalam memenuhi kebutuhan konsumen secara cepat, tepat dan dengan harga yang bersaing, serta kreatif untuk menciptakan inovasi produk atau jasa yang dihasilkan, manajemen yang selalu berkembang sehingga mampu mengatasi tingkat kerumitan dan perubahan yang terjadi setiap saat.

Minimnya informasi mengenai jumlah permintaan dan persediaan produk di setiap negara sangat mempengaruhi perputaran barang. Sebagai contoh ada 5 industri dengan jenis produk yang sama mengirim ke negara Australia dimana permintaan produk hanya sedikit. Tanpa adanya informasi yang tepat kelima indutri hanya melakukan ekspor produk tanpa mempertimbangkan ketersediaan produk di negara tersebut. Sehingga jumlah produk yang berada di negara Australia melebihi jumlah permintaan, hal ini mengakibatkan adanya penumpukan produk dan indutri mengalami kerugian dikarenakan minimnya tingkat penjualan. Produk dengan perputaran cepat adalah barang yang habis terjual dalam waktu yang relatif cepat. 
Tabel 1. Contoh data kategori cocoa beans

\begin{tabular}{|c|c|c|c|c|c|c|c|}
\hline \multirow[t]{3}{*}{ Jenis Product } & \multicolumn{7}{|c|}{ Nama Perusahaan- Negara } \\
\hline & \multicolumn{3}{|c|}{$\begin{array}{l}\text { Alba Impex And Alba } \\
\text { International-Bangladesh }\end{array}$} & \multicolumn{3}{|c|}{ Tetol - slovenia } & \multirow[t]{2}{*}{ dst } \\
\hline & Stok & Permintaan & $\begin{array}{l}\text { Daya } \\
\text { Saing }\end{array}$ & Stok & Permintaan & $\begin{array}{l}\text { Daya } \\
\text { Saing }\end{array}$ & \\
\hline Cocoa Beans & 10 & 100 & 87 & dst & dst & dst & \\
\hline Whole Or Broken & 100 & 50 & 100 & dst & dst & dst & \\
\hline $\begin{array}{l}\text { Cocoa Raw Or } \\
\text { Roasted }\end{array}$ & 89 & 200 & 50 & dst & dst & dst & \\
\hline Cocoa frozen & & & & & & & \\
\hline
\end{tabular}

Keterangan :

Stok : jumlah persediaan di masing-masing buyer/negara (sedikit, sedang, banyak)

Permintaan : jumlah rata-rata penjualan (sedikit, sedang, banyak)

Daya saing : jumlah produk yang masuk di masingmasing buyer (Rendah, tinggi)

Penentuan market ekspor yang tepat berdasarkan kriteria-kriteria yang dibutuhkan adalah salah satu upaya yang dilakukan para pelaku bisnis sehingga dapat meningkatkan keuntungan dan menekan kerugian akibat resiko terlambatnya perputaran produk.

Ekspor produk pada UMKM merupakan hal yang butuh perhatian lebih dengan pertimbangan antara lain (1) keterbatasan finansial dari UMKM dalam memproduksi komoditas (2) Sulitnya mengetahui kebutuhan pasar ekspor, (3) Sulitnya mengetahui cepat lambatnya perputaran barang di Market tersebut.

aplikasi Market Matching untuk penentuan lokasi pemasaran dan jumlah produk yang harus diekspor menggunakan kontrol fuzzy yang diharapkan dapat menekan angka kerugian akibat tersendatnya perputaran barang sehingga menguntungkan bagi para UMKM. Tujuan khusus yang ingin dicapai penelitian ini adalah dapat mengimplementasikan sistem penentuan lokasi pemasaran dan jumlah produk yang harus diekspor berbasis tingkat permintaan, persediaan dan daya saing antar industri sejenis menggunakan kontrol fuzzy yang dapat mengurangi kerugian akibat penumpukan persediaan barang yang terlalu banyak dan memberikan keuntungan dari hasil penjualan.

Aplikasi Market Matching bertujuan menghasilkan rekomendasi tujuan ekspor sesuai kategori produk dan tingkat kebutuhan importir yang dioperasikan UMKM melalui internet. Dengan aplikasi ini, UMKM akan mendapatkan kemudahan dalam mengekspor produknya. Dengan demikian maka komoditas yang diekspor akan semakin meningkat

\section{LANDASAN TEORI}

\section{Sistem Fuzzy}

Penggunaan metode Fuzzy yang merupakan cabang metode Sistem Pendukung Keputusan. Studi kasus yang digunakan adalah pemilihan importir yang tepat dengan jumlah yang tepat, sehingga ekspor yang dilakukan oleh UMKM berlangsung efisien. Bahan yang diteliti adalah proses pemasaran, data komoditas, data pengimpor dari semua benua.

\section{Market Matching}

Salah satu strategi pemsaran adalah STP (Segmentation, Targeting, Positioning)

1. Market Segmentation.
"Segmentasi Global Marketing adalah proses identifikasi segmen-segmen spesifik, baik dalam bentuk kaumpulan-kumpulan negara/individu konsumen dari para pelanggan potensial dengan atribut-atribut homogen yang kemungkinan dari para pelanggan memperlihatkan respon serupa terhadap bauran pemasaran sebuah perusahaan" (Hasan dan Katsanis dalam Ade Ismi)

2. Market Targeting

Setiap perusahaan dapat masuk ke dalam satu atau beberap segmen pasar. Setelah perusahaan mendefinisikan segmen pasarnya, market targeting mengevaluasi ketertarikan dari masing-masing segmen dan memilih segmen pasar. " Market Targeting adalah sebuah proses ketertarikan setiap segmen pasar dan memilih satu atau lebih segmen untuk dimasuki (Craven dalam Ade Ismi)

3. Market Positioning

Positioning menurut Tjiptono dalam Ade Ismi menjelaskan bahwa keberhasilan Positioning sangat ditentukan oleh kemampuan sebuah perusahaan untuk mendiferensiasi dirinya secara efektif dibandingkan para pesaingnya, akan mampu memposisikan diri di dalam pikiran konsumen terhadap produk yang ditawarkan, sehingga terbentuk produk perusahaan mendapat perhatian dari konsumen.

\section{METODE PENELITIAN}

Rancangan penelitian ini merupakan kombinasi antara penelitian eksperimental dan applied research untuk mendesain sistem Market Matching dengan metode fuzzy control. Beberapa tahapan tersebut adalah:

1. Identifikasi permasalahan dan Sistem Ekspor pada UMKM.

2. Analisa dan desain sistem yang disesuaikan dengan permasalahan yang ada

3. Pengembangan aplikasi market matching menggunakan metode fuzzy control

Ide dasar di balik fuzzy control adalah menyusun ulang skema dengan menerapkan Kontrol Fuzzy untuk menentukan besarnya arus pembelian ulang untuk setiap produk Analisa dan pengembangan pembangunan sistem menggunakan kontroler fuzzy dalam penelitian ini menggunakan tiga elemen yang diperlukan : Kumpulan aturan Fuzzy Control, mekanisme inference, dan interface output.

Penentuan variable dalam Fuzzy adalah variable yang digunakan untuk penerapan aturan-aturan dalam memecahkan masalah. Variable yang digunakan dalam aplikasi market matching antara lain:

Variabel Input
a. Stock
b. Capacity
c. Competitive
Variabel output
a. Ekspor

Aturan-aturan yang berlaku dalam proses market matching akan dikonversi dalam bentuk matriks Rule, Aturan-aturan tersebut antara lain : 
[R1] IF stock SEDIKIT AND capacity SEDIKIT AND competitive RENDAH THEN ekspor SEDANG [R2] IF stock SEDIKIT AND capacity SEDIKIT AND competitive TINGGI THEN ekspor RENDAH [R3] IF stock SEDIKIT AND capacity BANYAK AND competitive RENDAH THEN ekspor TINGGI [R4] IF stock SEDIKIT AND capacity BANYAK AND competitive TINGGI THEN ekspor SEDANG [R5] IF stock SEDANG AND capacity SEDIKIT AND competitive RENDAH THEN ekspor SEDANG [R6] IF stock SEDANG and capacity SEDIKIT AND competitive TINGGI THEN ekspor RENDAH [R7] IF stock SEDANG AND capacity BANYAK AND nd competitive RENDAH THEN ekspor TINGGI [R8] IF stock SEDANG AND capacity BANYAK AND competitive TINGGI THEN ekspor SEDANG [R9] IF stock BANYAK AND capacity SEDIKIT AND competitive RENDAH THEN ekspor SEDANG [R10] IF stock BANYAK AND capacity SEDIKIT AND competitive TINGGI THEN ekspor RENDAH [R11] IF stock BANYAK AND capacity BANYAK AND competitive RENDAH THEN ekspor SEDANG [R12] IF stock BANYAK AND capacity BANYAK AND competitive TINGGI THEN ekspor RENDAH

\section{HASIL DAN PEMBAHASAN}

\section{A. Perancangan Sistem}

Use case diagram aplikasi market matching dapat dilihat pada gambar 1 .

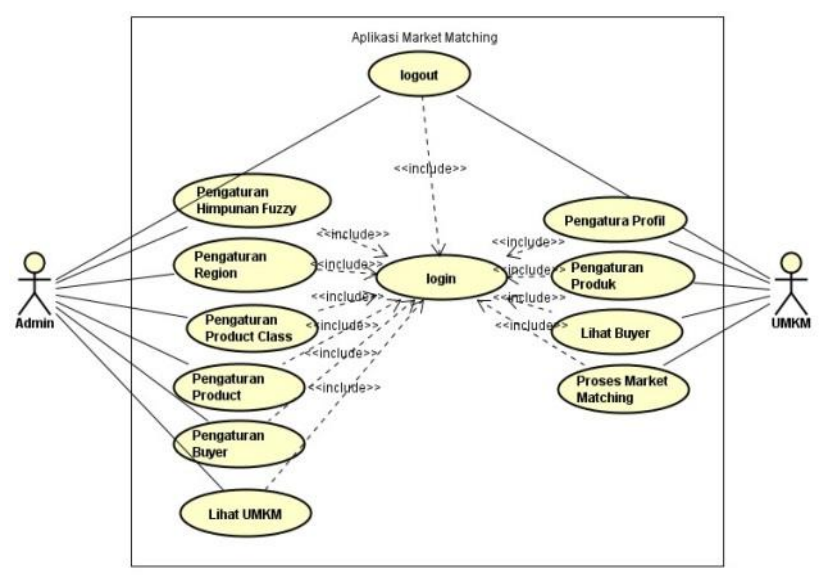

Gambar 1 Use Case Aplikasi Market Matching

Pada perancangan Use Case, aplikasi Market Matching terdiri dari dari 2 level user diantaranya UMKM dan admin. Admin melakukan Pengaturan Himpunan Fuzzy, Pengaturan Region Buyer, Pengaturan Product Buyer, Pengaturan Buyer. Sedangkan pada UMKM, terdapat Pengaturan Profil UMKM, Pengaturan Produk UMKM, dan Proses Market Matching.

Pada Diagram Hierarki yang ditampilkan pada gambar 2, Sistem Market Matching dibagi dua bagian, yaitu : UMKM dan ADMIN. Pada UMKM, terdapat proses Registrasi, Login, dan Profil UMKM.

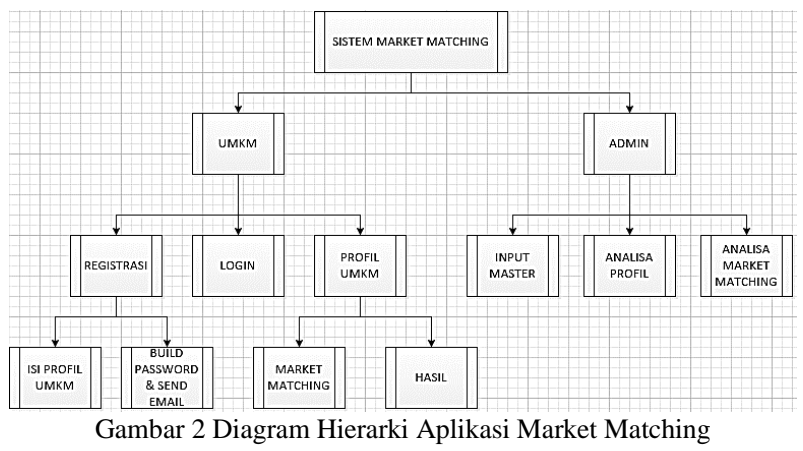

Diagram relasi database aplikasi market matching dapat dilihat pada gambar 3.

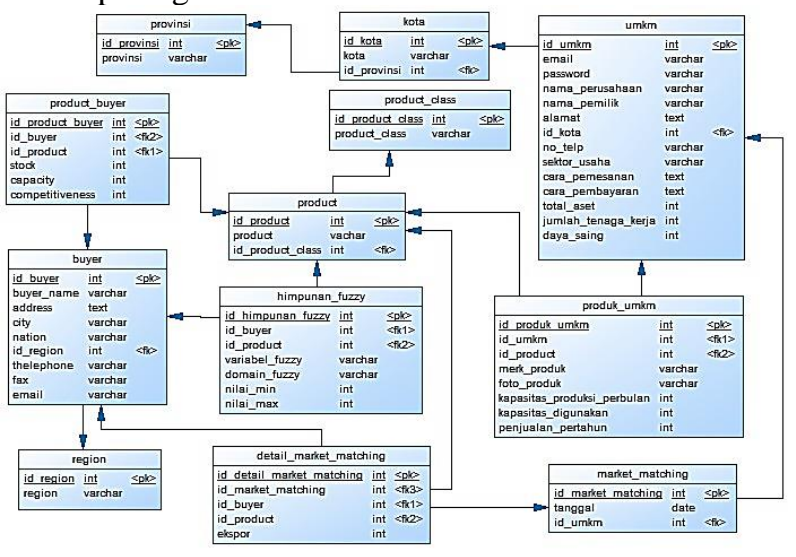

Gambar 3 Diagram relasi database Aplikasi Market Matching

\section{B. Hasil Aplikasi Market Matching}

Setelah UMKM melakukan Registrasi dan Login, UMKM dapat mengisi Profil UMKM untuk menambah produknya, seperti pada gambar 4 .

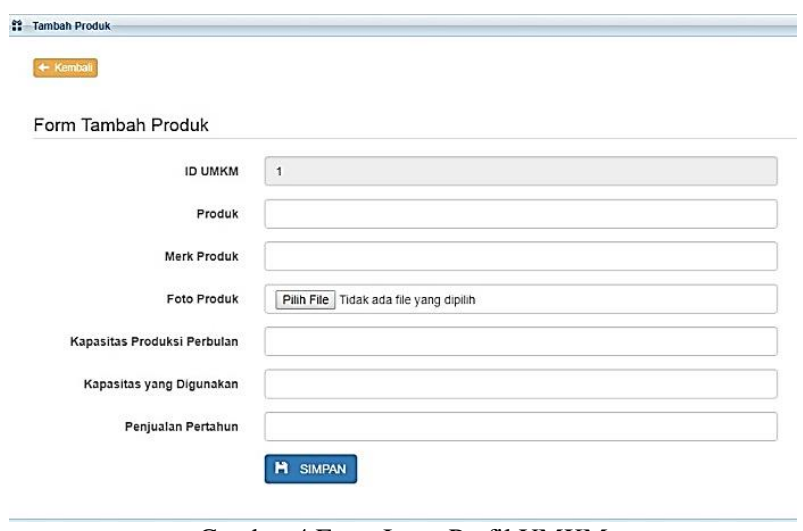

Gambar 4 Form Input Profil UMKM

Setelah ditambahkan produk UMKM, maka dapat ditampilkan halaman daftar produk dari UMKM seperti pada gambar 5 .

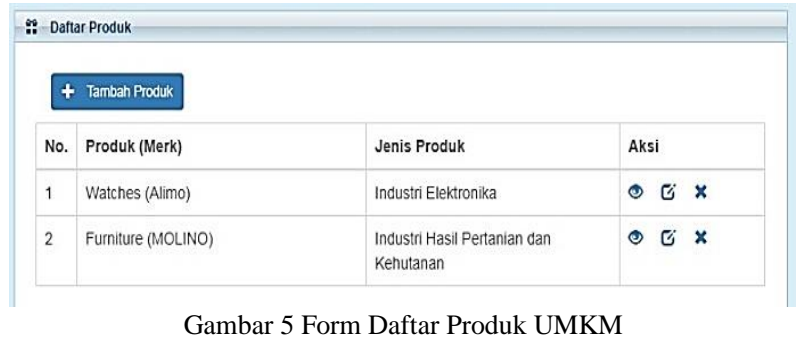


Pada Login UMKM, tampilan daftar data buyer yang dapat dilihat seperti pada gambar 6. Pada halaman ini terdapat fitur pencarian data buyer berdasarkan nama product, jenis product dan region.

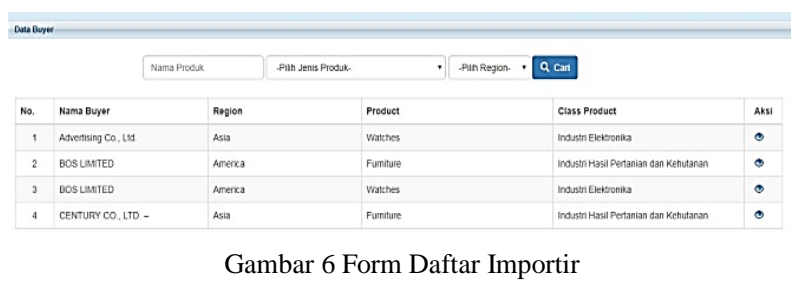

Selanjutnya UMKM dapat mencari Importir tujuan ekspor melalui tombol seperti pada gambar 7 dengan mengikuti petunjuk yang tertulis.

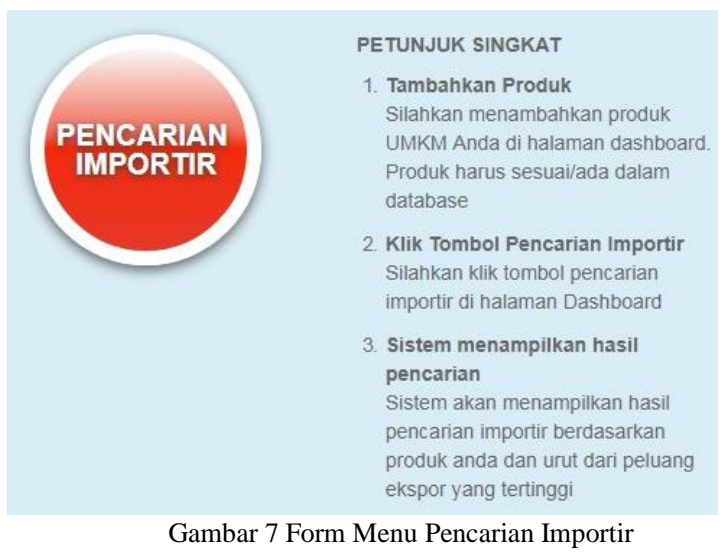

Hasil dari pencarian Importir ditampilkan pada Halaman hasil market matching seperti pada gambar 8 .

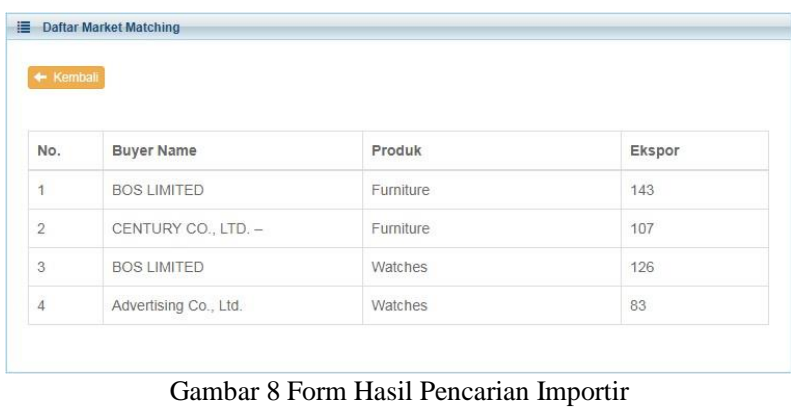

Hasil market matching berupa sejumlah data buyer yang berdasarkan jenis product UMKM yang ditampilkan secara urut dari jumlah ekspor yang tertinggi.

\section{KESIMPULAN DAN SARAN}

\section{A. Kesimpulan}

Dari hasil penelitian yang sudah dilakukan, maka dapat diambil kesimpulan sebagai berikut :

1. Aplikasi Market Matching dapat menghasilkan rekomendasi tujuan ekspor sesuai kategori produk dan tingkat kebutuhan importir yang dioperasikan UMKM melalui internet.

2. Aplikasi Market Matching berbasis web dapat memberi kemudahan UMKM dalam mengakses data secara online untuk menentukan tujuan ekspor produknya.

\section{B. Saran}

Untuk perbaikan dari sistem ini, peneliti memberikan beberapa saran antara lain :

1. Aplikasi dapat dikembangkan berbasis Android agar lebih mudah penggunaanya.

2. Database harus sering diupdate datanya untuk mendapatkan hasil yang lebih akurat.

\section{DAFTAR PUSTAKA}

[1] Abdulkadiroglu, Atila dan Tayfun Sonmez, Matching Markets: Theory and Practice, Duke University and Boston college, World Congress Survey, 2010

[2] Chih-Hsun Hsieh, Optimization of Fuzzy Inventory Models under Fuzzy Demand and Fuzzy Lead Time, Tamsui Oxford Journal of management Sciences, Vol. 20, No. 2 (21-36), 2004

[3] Darmayani, Ade Ismi, dkk. Strategi Pemasaran Kerajinan Buah Kering untuk Meningkatkan Nilai Ekspor pada UD. INDO NATURE, Lombok-NTB. Jurnal Administrasi Bisnis (JAB) Vol 11 No 1 juni 2014

[4] Enchenique, Federico dan Jorge Oviedo, a Theory of stability in many-to-many matching market, Theorical Economics, http://econtheory.org, 2006

[5] Galichon, Alfred. Theoretical and Empirical Aspects of Matching Markets, Economics Department, Columbia University, 2011

[6] Igit Purwahyudi (2002), How 2 Use DT-51 PetraFuz, Petra, Surabaya, Indonesia

[7] Kusumadewi, S. \& Purnomo, H., 2010. Aplikasi logika Fuzzy untuk pendukung keputusan. Graha Ilmu: Yogyakarta.

[8] Lestari, Ni Putu Nina Eka, Strategi Pemberdayaan Industri Kecil Kerajinan Ukiran Kayu di Kabupaten Gianyar Provinsi Bali, 2014

[9] Nurhasanah, Nunung dan Siti Nur Fadlilah A, Pemodelan Strategi Pemasaran produk Barang Jadi Tekstil Berdasarkan Pendekatan Simulasi Sistem Dinamik pada Industri Kecil Menengah di Kota Bogor, J@TI Undip, Vol VII, No 1, Januari 2012

[10] Syahdi, Oni Fajar, dkk. Analisis Permintaan Pasar Ekspor terhadap Produk Udang Beku (Frozwn Srimphs/Prawn) Indonesia, 2013, Agrica (jurnal Agribisnis Sumatera utara) Vol. 1 No.1/ Juli 2013.

[11] Sonalitha, Elta, Moechammad Sarosa, dan Agus Naba. Pemilihan Pemasok Bahan Mentah pada Restoran Menggunakan Metode Fuzzy Analitycal Hierarchy Process, Jurnal EECCIS vol 9, No1, 2015

[12] Ta-Wei Hung, S.-C. Fang, H.L.W. Nuttle, R.E. King (1999), A Fuzzy-Control-Based Quick Response Reorder Scheme for Retailing of Seasonal Apparel. North Carolina State University, Raleigh, N.C., U.S.A.

[13] Wulandari, Fera Tri. Implementasi Fuzzy Topsis dalam Perencanaan Strategi Bisnis, http://journal.unwidha.ac.id/, Magistra Vol 25, No 85,2013

[14] Yeon-Koo Che, Olivier Tercieux, Efficiency and Stability in Large Matching Markets,Cowles Foundation For Research in Economics Yale University, 2015 